\title{
Botânica no Ensino Superior: o que pensam os discentes do Amapá (Amazônia,
}

\section{Brasil)}

\author{
Botany in Higher Education: what students from Amapá (Amazonia, Brazil) think \\ La botánica en la educación superior: lo que piensan los estudiantes de Amapá (Amazonia, Brasil)
}

Recebido: 20/04/2021 | Revisado: 26/04/2021 | Aceito: 03/05/2021 | Publicado: 16/05/2021

\author{
Robson Marinho Alves \\ ORCID: https://orcid.org/0000-0002-4075-3539 \\ Instituto Federal de Educação, Ciência e Tecnologia do Amapá, Brasil \\ E-mail: robson.alves@ifap.edu.br \\ Ana Cristina Andrade de Aguiar Dias \\ ORCID: https://orcid.org/0000-0001-8779-3557 \\ Universidade Federal do Pará, Brasil \\ E-mail: acaaguiar@yahoo.com.br \\ André dos Santos Bragança Gil \\ ORCID: https://orcid.org/0000-0002-0833-9856 \\ Museu Paraense Emílio Goeldi, Brasil \\ andregil@museu-goeldi.br
}

\begin{abstract}
Resumo
O presente trabalho teve como objetivo descrever as dificuldades encontradas pelos discentes no processo ensinoaprendizagem, dos conteúdos de Botânica em cursos de licenciatura em Ciências Biológicas e Naturais ofertados por Instituições de Ensino Superior (IES) públicas do estado do Amapá. Os dados foram coletados a partir da utilização de questionários, contendo perguntas referentes as particularidades dos discentes e do curso, os obstáculos relacionados aos conteúdos e carga horária das disciplinas, a metodologia docente e o que pode ser melhorado no ensino de Botânica. As respostas destacam os empecilhos que limitam a aprendizagem dos discentes no que se referem às estratégias didáticas aplicadas pelos docentes no ensino das disciplinas, a exiguidade de aulas práticas, a escassez de material didático e de espaços específicos para as aulas e a carga horária insuficiente para estudar as disciplinas de Botânica. Os resultados apresentados neste estudo recomendam o aperfeiçoamento do ensino de Botânica nos cursos de licenciaturas analisados, principalmente no que tange as estratégias e procedimento metodológico docente ao ensinar as disciplinas de Botânica.
\end{abstract}

Palavras-chave: Aprendizagem; Ensino; Licenciatura em ciências biológicas e naturais.

\begin{abstract}
The present study aimed to describe the difficulties encountered by students in the teaching-learning process, of the contents of Botany in degree courses in Biological and Natural Sciences offered by public Higher Education Institutions (HEIs) in the state of Amapá. The data were collected from the use of questionnaires, containing questions regarding the particularities of the students and the course, the obstacles related to the content and workload of the subjects, the teaching methodology and what can be improved in the teaching of Botany. The responses highlight the obstacles that limit students' learning with regard to the didactic strategies applied by teachers in the teaching of subjects, the lack of practical classes, the scarcity of didactic material and specific spaces for classes and the insufficient workload for students. study the disciplines of botany. The results presented in this study recommend the improvement of the teaching of Botany in the undergraduate courses analyzed, mainly with regard to the strategies and methodological teaching procedure when teaching the disciplines of Botany.
\end{abstract}

Keywords: Learning; Teaching; Degree in biological and natural sciences.

\section{Resumen}

El presente estudio tuvo como objetivo describir las dificultades encontradas por los estudiantes en el proceso de enseñanza-aprendizaje, de los contenidos de Botánica en las carreras de Licenciatura en Ciencias Biológicas y Naturales que imparten las Instituciones de Educación Superior (IES) públicas del estado de Amapá. Los datos fueron recolectados a partir del uso de cuestionarios, que contienen preguntas sobre las particularidades de los estudiantes y el curso, los obstáculos relacionados con el contenido y carga de trabajo de las asignaturas, la metodología de enseñanza y lo que se puede mejorar en la enseñanza de Botánica. Las respuestas destacan los obstáculos que limitan el aprendizaje de los estudiantes en cuanto a las estrategias didácticas aplicadas por los docentes en la docencia de las asignaturas, la falta de clases prácticas, la escasez de material didáctico y espacios específicos para las clases y la insuficiente carga de trabajo de los estudiantes. disciplinas de la botánica. Los resultados presentados en este estudio 
recomiendan la mejora de la enseñanza de la Botánica en las carreras de grado analizadas, principalmente en lo que se refiere a las estrategias y procedimiento metodológico de enseñanza a la hora de impartir las disciplinas de Botánica.

Palabras clave: Aprendizaje; Docencia; Licenciatura en ciencias biológicas y naturales.

\section{Introdução}

A aptidão de aprender nos seres humanos ocorre a todo o momento de maneira cognitiva e consciente (Freire, 1987). É interessante destacar sobre a prática de ensinar. Segundo Paulo Freire, ensinar não é transferir conhecimento, é respeitar a autonomia e a identidade do educando. Para passar conhecimento o educador deve estar envolvido com ele, para envolver os educandos e estimulá-los a desenvolverem seus pensamentos (Freire, 1996).

A Botânica está incorporada no cotidiano da população, sendo importante conhecer e entender a sua relevância. Mesmo fazendo parte da rotina da população, as plantas geralmente são vistas como elementos inertes e as pessoas não conseguem notar e discernir a importância das plantas para o ambiente, entendimento esse conhecido como "cegueira botânica" (Wandersee \& Schussler, 2001; Hershey, 2002; Katon, Towata \& Saito, 2013; Salatino \& Buckeridge, 2016; Fonseca \& Ramos, 2018; Ursi, Freitas \& Vasques, 2021).

$\mathrm{Na}$ educação superior, a Botânica tem destaque nos currículos dos cursos de licenciaturas em Ciências Biológicas (Lucas, 2014). Entretanto trabalhos publicados destacam que os conteúdos de Botânica nas licenciaturas exibem uma peculiaridade decorativa, repleta de definições técnicas de complicada compreensão (Towata, Ursi \& Santos, 2010; Silva \& Sano, 2011; Silva, 2013; Santos et al., 2015; Fonseca \& Ramos, 2017; 2018).

O ensino de Botânica é uma proposição educacional que vem gerando debates nas instituições de ensino superior de formação docente e vem sendo marcado na educação brasileira por uma sequência de adversidades. No qual o maior deles está relacionado ao ensinamento desse tema de forma convencional e descontextualizado, causando desinteresse nos discentes pelos conteúdos abordados (Katon, Towata \& Saito, 2013). Além disso, o modo de ensinar as disciplinas nos cursos de licenciatura gira em torno de formar profissionais "Biólogos" em detrimento da formação profissional de docentes (Figueiredo et al., 2012; Silva, 2013).

As Instituições de Ensino Superior (IES) incumbidas da formação docente experimentam no cotidiano o desafio de formar profissionais bem competitivos para o mercado de trabalho e flexível às mudanças educacionais (Dutra \& Gullich, 2016). Dentro desse contexto, faz-se necessário discutir nas IES de Licenciatura em Ciências Biológicas e Naturais, como o ensino da Botânica está sobrevindo nestas instituições. No qual é perceptível a necessidade de pesquisar os obstáculos que limitam a aprendizagem dos discentes, principalmente em relação as estratégias didáticas aplicadas pelos docentes no ensino das disciplinas de Botânica. (Santos et al., 2015; Fonseca \& Ramos, 2018).

Em relação ao que foi evidenciado, julgamos necessário conhecer as problemáticas que os licenciandos enfrentam nos seus cursos na aprendizagem das disciplinas de Botânica, principalmente na região amazônica, para depois propor possíveis estratégias que visam melhorar a qualidade do ensino de Botânica nos cursos de Licenciatura em Ciências Biológicas e Naturais. A relevância da pesquisa é essencial para conhecer a real situação vivenciada entre docentes e discentes dentro do processo ensino-aprendizagem frente às atuações possíveis no ensino da Botânica.

A discussão sobre o tema, além do aspecto prático, é muito relevante para o meio acadêmico. Nesse contexto, a realização de estudos a respeito do Ensino de Botânica nas licenciaturas pode ser o início de um processo de transformação que começa na Universidade e estende seus reflexos para a realidade social e ambiental.

Dessa forma, o presente trabalho teve como objetivo principal analisar os obstáculos encontrados pelos discentes no processo ensino-aprendizagem dos conteúdos de Botânica em cursos de Licenciatura em Ciências Biológicas e Naturais ofertados por Instituições de Ensino Superior (IES) públicas do estado do Amapá. 


\section{Metodologia}

A pesquisa foi empreendida em IES públicas do estado do Amapá, localizadas em Macapá/AP (Universidade Federal do Amapá - UNIFAP; Universidade Estadual do Amapá - UEAP), Laranjal do Jari/AP (Instituto Federal do Amapá - IFAP) e Oiapoque/AP (Universidade Federal do Amapá - UNIFAP). Os cursos elegidos para a realização da pesquisa nessas IES foram os de Licenciatura em Ciências Biológicas (IFAP e UNIFAP) e Naturais (UEAP). Destaca-se que, todas as instituições de ensino superior públicas do Amapá, que oferecem os cursos citados, participaram do presente estudo.

Este trabalho caracterizou-se por uma pesquisa descritiva onde foram realizadas análises e interpretações de dados, de forma qualitativa e quantitativa. Para Pereira et al. (2018), os métodos qualitativos estão sujeitos a interpretação e opinião do pesquisador sobre o estudo, onde muitas vezes esses métodos qualitativos se transformam em quantitativos pelo uso de questões fechadas. Dos quais os métodos quantitativos, os dados coletados geram números que podem ser analisados por técnicas matemáticas aceitáveis ao trabalho.

Foram entrevistados cento e dezessete (117) discentes, que concluíram todas as disciplinas de Botânica oferecidas na grade curricular dos cursos de Licenciatura em Ciências Biológicas e Naturais das IES públicas pesquisadas, no universo de 130 licenciandos aptos a participar da pesquisa.

O projeto de pesquisa foi aprovado pelo Comitê de Ética do Instituto de Pesquisas Cientificas e Tecnológicas do Estado do Amapá (CEP/IEPA), sob o parecer de número 3.290.337 e data de aprovação 28/04/2019. Conforme a Resolução 466/12 para pesquisas com seres humanos, todas as pessoas entrevistadas durante a execução da pesquisa assinaram um Termo de Consentimento Livre e Esclarecido (TCLE).

Os dados para a referida pesquisa foram coletados no período de maio a julho de 2019, a partir da aplicação de um questionário (Instrumento de Coleta de Dados - ICD), contendo perguntas objetivas e discursivas, relacionadas aos seguintes tópicos: aspectos gerais dos acadêmicos e dos cursos; dificuldades relacionadas aos conteúdos e carga horária das disciplinas de Botânica; estratégias e recursos didáticos usados pelos docentes para o desenvolvimento das disciplinas; sugestões de melhorias no ensino de Botânica na licenciatura. Os coordenadores e professores das IES públicas citadas autorizaram a aplicação dos questionários através da assinatura da carta de anuência.

Após a verificação dos ICD, os resultados quantitativos foram apreciados e tabulados utilizando as técnicas da estatística descritiva (frequência absoluta e relativa), com o auxílio do "Microsoft Office Excel 2013", a partir do qual foram produzidos gráficos descritivos. As respostas das questões discursivas foram tratadas a partir da técnica qualitativa de análise de conteúdo (Bardin, 2011; Strauss \& Corbin, 2008). Os dados obtidos foram tabulados, organizados e sistematizados por meio de análise e interpretação dos conteúdos presentes nas respostas, que representam o conjunto de ideias comuns ao grupo pesquisado a fim de compreendê-las de acordo com os fundamentos teóricos desta pesquisa. Os resultados foram apurados com a intenção de verificar as categorias com maior incidência de respostas, originando tabelas e gráficos.

Após a análise das respostas foi possível verificar as dificuldades e as estratégias metodológicas usadas na aprendizagem das disciplinas de Botânica nos cursos de Licenciatura em Ciências Biológicas e Naturais, evidenciando possíveis melhorias no processo de aprendizagem, bem como recomendações de sugestões metodológicas para o ensino de Botânica nos cursos de formação de professores.

\section{Resultados e Discussão}

\subsection{Aspectos dos discentes e afinidade com as disciplinas de Botânica}

Os cento e dezessete (117) licenciandos, em Ciências Biológicas e Naturais, que responderam ao questionário representam 90\% dos discentes aptos a participar da pesquisa, com faixa etária entre 19 e 49 anos, sendo $62 \%$ destes do sexo feminino. Dos entrevistados, 91,45\% concluíram a educação básica (ensino médio) na rede pública de ensino (Figura 1). 
Figura 1. Gênero, faixa etária e conclusão da educação básica dos participantes da pesquisa.

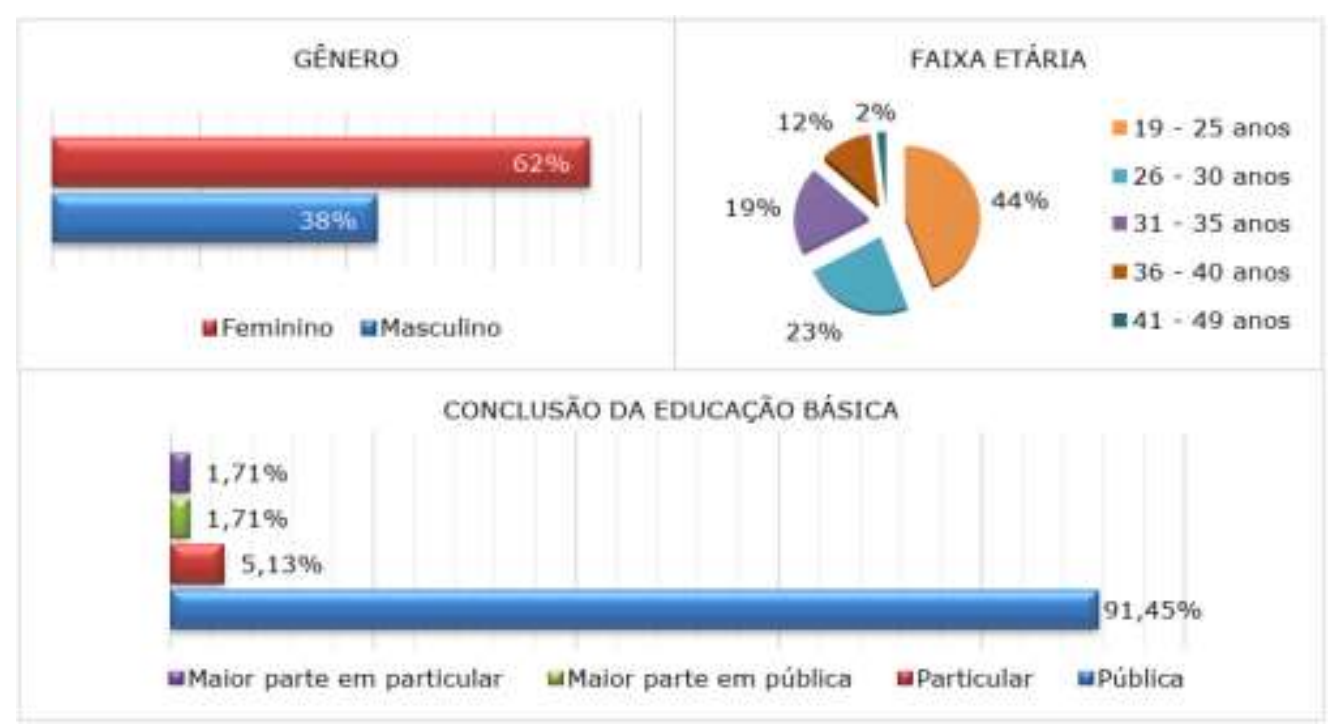

Fonte: Autores.

Os resultados apontaram que 71\% (83) dos discentes tiveram aulas de Botânica no ensino médio (Figura 2). Nos relatos, a maioria referiu que as aulas possuíam cunho muito enfadonho e focado principalmente na preparação para o Exame Nacional do Ensino Médio (ENEM). Na visão dos licenciandos, os conteúdos ensinados de Botânica na educação básica (ensino médio) foram bastante conteudista e decorativa, com ausência de aulas práticas, tornando a disciplina desinteressante no ato de aprender. É notório que tais aulas retratam a forma como os assuntos de Botânica foram abordados na educação básica, sendo conteúdos muito teóricos e descontextualizados e com escassez de atividades práticas (Kinoshita et al., 2006; Prigol \& Giannotti, 2008; Ursi et al., 2018).

As informações coletadas demonstram que $29 \%$ (34) dos alunos ingressantes não tiveram aulas de Botânica em nenhum momento no ensino médio (Figura 2). Fato esse que ratifica a distância do estudante em relação às plantas e o não "gostar" das disciplinas vinculadas a esta área de conhecimento durante o curso. Consequentemente, um distanciamento da sua realidade e de questões ambientais, onde é evidente que não se pode preservar o que não se conhece. Realidade esta, evidenciada no trabalho de Silva et al. (2019), onde o saber botânico através da seringueira fora investigado na população de Belém/PA, com o intuito de elaborar estratégias didáticas para melhorar o ensino-aprendizado, baseado na relação entre a vivência de cada indivíduo e a Botânica.

Durante a licenciatura, ao cursarem as disciplinas de Botânica, 71,8\% (84) dos discentes responderam que apresentam afinidade (gosta; gosta muito) com as mesmas (Figuras 2). Situação curiosa é que os mesmos alunos relataram que, mesmo gostando da disciplina, apresentam alguma dificuldade para compreender os conteúdos durante as aulas, circunstância essa declarada pela terminologia dos assuntos envolvidos e a metodologia utilizada para o ensino da mesma, onde resultado análogo foi encontrado no trabalho de Santos et al. (2015). 
Figura 2. O ensino da Botânica no ensino médio e a afinidade dos licenciandos com as disciplinas de Botânica nas IES públicas do Amapá, Brasil.

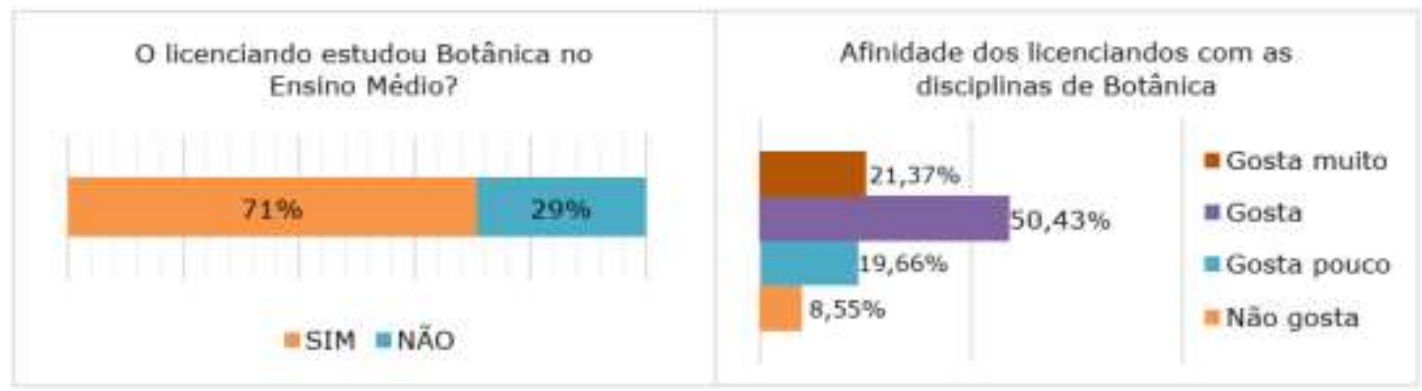

Fonte: Autores.

\subsection{Os obstáculos encontrados pelos discentes para compreender os conteúdos de Botânica}

As dificuldades declaradas pelos entrevistados foram agrupadas em categorias, de acordo com a tabela 1, que exibe os principais obstáculos considerados pelos discentes para assimilar os conteúdos ministrados durante as disciplinas de Botânica. De acordo com as respostas obtidas, 90,6\% (106) dos licenciandos apresentam agruras para compreender os conteúdos de Botânica.

É importante enfatizar a relação direta entre as principais dificuldades citadas pelos discentes (Tabela 1), que foram à metodologia docente $(27,35 \%)$ e a escassez de aulas práticas $(23,08 \%)$, com o procedimento utilizado pelos docentes ao ensinar as disciplinas de Botânica. Fato esse que corrobora com os estudos que apontam as mesmas dificuldades de aprendizagem (Santos et al., 2015; Fonseca \& Ramos, 2018). Os discentes, do mesmo modo apontam a ausência de conhecimento prévio oriundo da educação básica, a exorbitância de informações técnicas, a carência de equipamentos e de aulas práticas, como obstáculos para o processo de aprendizagem dos assuntos botânicos.

Tabela 1. Dificuldades encontradas pelos discentes para compreender os conteúdos de Botânica.

\begin{tabular}{|c|c|c|c|}
\hline Categorias & Dificuldades & Total de respostas & $\%$ \\
\hline \multirow{2}{*}{$\begin{array}{c}\text { Aulas práticas } \\
(23,08 \%)\end{array}$} & Escassez de aulas práticas & 21 & $17,95 \%$ \\
\hline & Muita informação teórica e poucas práticas & 06 & $5,13 \%$ \\
\hline \multirow{4}{*}{$\begin{array}{l}\text { Estrutura da IES } \\
\qquad(9,41 \%)\end{array}$} & Falta de laboratórios & 05 & $4,27 \%$ \\
\hline & Carência de equipamentos e material laboratorial & 04 & $3,42 \%$ \\
\hline & Poucos livros de botânica na biblioteca do Campus & 01 & $0,86 \%$ \\
\hline & Ausência de técnicos na área de botânica & 01 & $0,86 \%$ \\
\hline \multirow{2}{*}{$\begin{array}{c}\text { Termos técnicos } \\
(18,8 \%)\end{array}$} & Diversidade e termos técnicos complexos & 11 & $9,40 \%$ \\
\hline & Identificação e nomenclatura botânica & 11 & $9,40 \%$ \\
\hline \multirow{3}{*}{$\begin{array}{c}\text { Metodologia } \\
\text { docente } \\
(27,35 \%) \\
\end{array}$} & Compreensão dos conteúdos ministrados & 11 & $9,40 \%$ \\
\hline & Ausência de conhecimento prévio oriundos da educação básica & 06 & $5,13 \%$ \\
\hline & Procedimento didático do docente aplicado ao ensino da disciplina & 15 & $12,82 \%$ \\
\hline \multirow{3}{*}{$\begin{array}{l}\text { Disciplinas } \\
(18,8 \%)\end{array}$} & Entendimento dos conteúdos de Fisiologia Vegetal & 07 & $5,98 \%$ \\
\hline & Discernimento dos termos utilizados na Sistemática Vegetal & 05 & $4,27 \%$ \\
\hline & Assimilação dos conteúdos de Histologia Vegetal & 02 & $1,71 \%$ \\
\hline \multicolumn{2}{|c|}{ Total de respostas dos entrevistados que apontaram dificuldades } & 106 & $90,60 \%$ \\
\hline \multicolumn{2}{|c|}{ Total de respostas dos entrevistados que não possuem dificuldades } & 11 & $9,40 \%$ \\
\hline \multicolumn{2}{|c|}{ Total de entrevistados } & 117 & $100 \%$ \\
\hline
\end{tabular}

Fonte: Autores.

As aulas práticas são imprescindíveis para o ensino de Botânica, pois concede aos licenciandos a capacidade de correlacionar à teoria com o cotidiano (Towata, Ursi \& Santos, 2010). Esse tipo de aula estimula o interesse dos alunos em aprender, que segundo Krasilchik (2008), deve assumir uma conjuntura investigativa com atividades que aprimorem a formação do conhecimento. Concatenar a teoria com a prática tornam as aulas mais substanciais e realistas, ampliando a 
relação do licenciando com o meio ambiente e sua capacidade de aprendizagem. Assim sendo, as ausências dessas aulas, reforçam as dificuldades de aprendizagem apresentadas pelos discentes, em relação aos conteúdos de Botânica ministrados durante o curso de licenciatura, onde os alunos não têm contato com os materiais botânicos, tornando-se assim simples expectadores em sala de aula.

Os obstáculos de aprendizagem apresentados nos fazem refletir na investigação de novas estratégias metodológicas que sejam capazes de minimizar tais adversidades. No qual o importante é estimular o aprendizado com técnicas que auxiliem o ensino com base nas particularidades de cada grupo acadêmico. Incrementar esses procedimentos requer investimento na formação pedagógica dos educadores, além da aquisição de material didático e espaço específico para ensinar as aulas de Botânica.

De acordo com os discentes entrevistados, os conteúdos de Sistemática vegetal (36\%) e Fisiologia vegetal (31\%) são os temas específicos de Botânica que eles têm menos afinidade, devido as dificuldades de assimilar esses assuntos em sala de aula (Figura 3). O grau de afinidade com as disciplinas citadas está diretamente correlacionado às dificuldades em aprender o conteúdo programático das mesmas.

As dificuldades apontadas pelos licenciandos em aprender Sistemática vegetal, está relacionada com a identificação das famílias botânicas e os termos técnicos usados nunca vistos antes. Tais dificuldades estão vinculadas a quantidade e o nível elevado dos conteúdos associado à maneira como são transmitidos aos alunos, sendo de forma descontextualizada e com poucas aulas práticas, sem aplicabilidade no dia a dia do educando. É importante salientar que a Sistemática vegetal contém bases na Morfologia vegetal, fato esse interessante, já que os licenciandos também exibem dificuldades em aprender morfologia vegetal que ajudará nas identificações Botânicas (Figura 3). Com relação a Fisiologia vegetal as dificuldades apresentadas estão associadas ao entendimento dos processos que abrangem metabolismo energético (fotossíntese e respiração celular). Nesse contexto é interessante ressaltar a necessidade de concatenar e aprender as outras áreas da Botânica que precede a fisiologia das plantas.

Figura 3. Os conteúdos de botânica que os discentes têm menos afinidade.

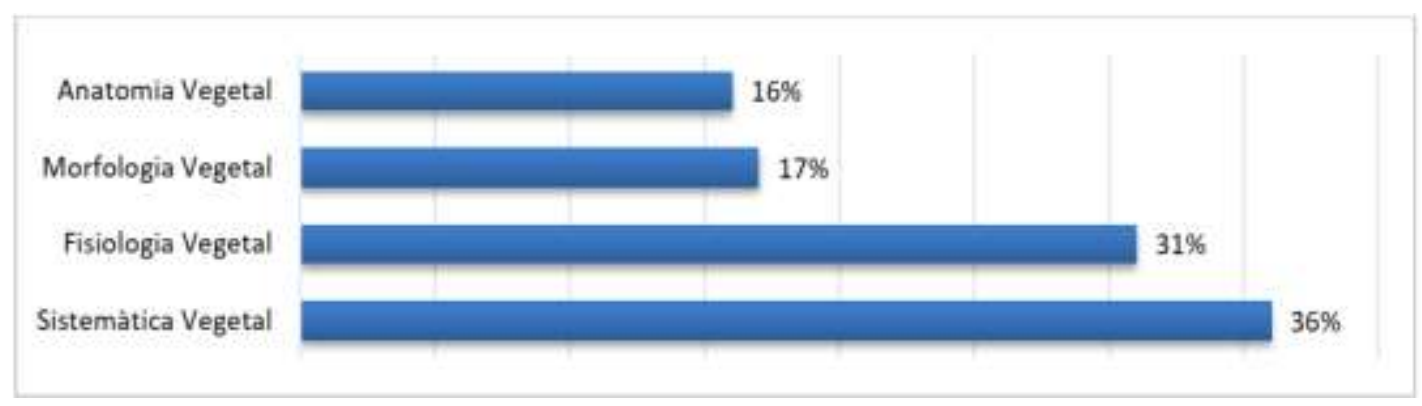

Fonte: Autores.

Convém enfatizar que essas disciplinas apresentam uma grande intensificação de conteúdos técnicos vinculados à formação profissional Botânica e não docente (Silva, 2013; Santos et al, 2015; Fonseca \& Ramos, 2018). Para Krasilchik (2008), disciplinas que denotam assuntos com muitos termos técnicos, tornam o ensino bastante conteudista, promovendo a falta de interesse dos alunos em aprendê-los. Desta forma, o interesse (afinidade) dos licenciandos para com as disciplinas mencionadas perpassa na maneira como ele foi instruído, por intermédio dos docentes, durante a sua formação acadêmica.

\subsection{O procedimento metodológico docente no ensino de Botânica}

Em relação ao procedimento metodológico do professor para ensinar as disciplinas de Botânica, 52\% (61) dos discentes relataram insatisfação na metodologia utilizada pelo docente para ministrar as aulas, pois não estava ocasionando 
aprendizagem significativa. A insatisfação mencionada não está relacionada ao conhecimento do educador sobre o tema, mas as estratégias utilizadas por eles em transmitir o conhecimento Botânico. No qual a principal estratégia adotada resume-se as aulas teóricas expositivas sem a realização de atividades práticas sobre o referido assunto ensinado (Figura 4).

O procedimento metodológico satisfatório (Figura 4) citado pelos discentes enfatizam o conhecimento Botânico e a experiência profissional dos docentes. Entretanto, os próprios discentes destacam a necessidade de utilizar novas estratégias de ensino vinculadas as aulas práticas. Por essa razão, mesmo os docentes apresentando um grande saber Botânico, eles necessitam de uma formação pedagógica continuada que auxilie na maneira de ensinar. Sendo essa qualificação constante e objetiva, acompanhando a realidade do cotidiano dos educandos.

Figura 4. A metodologia e os recursos utilizados pelo professor de Botânica.

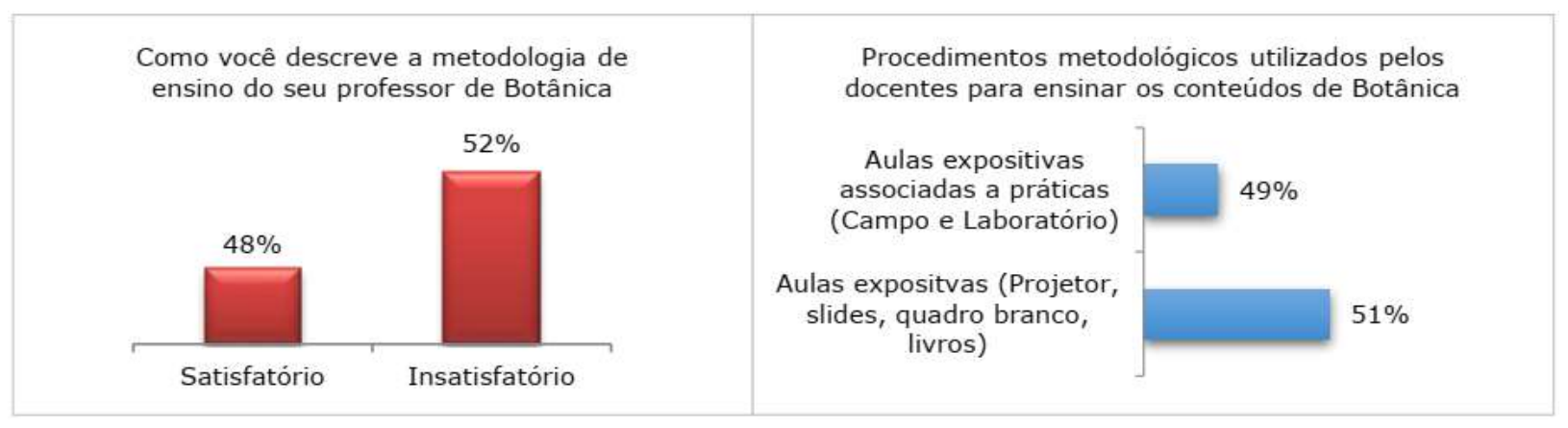

Fonte: Autores.

A verificação dos resultados destaca que $51 \%$ (60) dos licenciandos vivenciaram aulas exclusivamente teóricas expositiva com exiguidade de práticas de campo ou laboratorial (Figura 4). Conjuntura esta exteriorizada neste estudo por uma IES pública, que não apresenta nenhum laboratório e equipamentos para as práticas de microscopia e estereomicroscopia. É proeminente no estudo de Fonseca \& Ramos (2018), que os assuntos de Botânica lecionados nos cursos de Licenciatura em Ciências Biológicas são demasiadamente teóricos e descontextualizados. Também é perceptível, em algumas instituições participantes da pesquisa, o desprovimento de material didático e espaços específicos para ministrar as aulas de Botânica. É notório, diante dessas adversidades, que sobrevenha o predomínio de aulas expositivas com poucas atividades práticas (Frasson \& Campos, 2011).

É importante enfatizar que estamos passando por um processo de transição no ensino da Botânica, onde o momento é de buscar estratégias menos conteudista e que dê ao discente mais autonomia dentro do processo ensino-aprendizagem. Onde cursos de aperfeiçoamento com novas técnicas de ensino para as aulas de botânica, sejam essenciais na capacitação docente. Convêm ressaltar, diante do exposto, a oportunidade de abordar práticas de ensino que envolvam aprendizagem significativa como: o ensino híbrido, a sala de aula invertida, a aprendizagem baseada em problemas, a interdisciplinaridade e a contextualização com abordagem Ciência, Tecnologia, Sociedade e Ambiente (CTSA). As aplicações dessas estratégias são capazes de tornar as aulas de Botânica mais atraentes e com qualidade, sem desperdiçar o conteúdo programático da disciplina.

\subsection{A carga horária das disciplinas de Botânica}

Em relação à carga horária das disciplinas de Botânica, 55\% (64) dos discentes afirmam que à carga horária é insuficiente para concluir e praticar os conteúdos (Figura 5). Além disso, foi relatado que faltam planejamento e organização docente ao trabalhar as aulas buscando atingir aprendizagem significativa com os conteúdos repassados durante a realização da disciplina. 
Figura 5. A carga horária das disciplinas de Botânica.

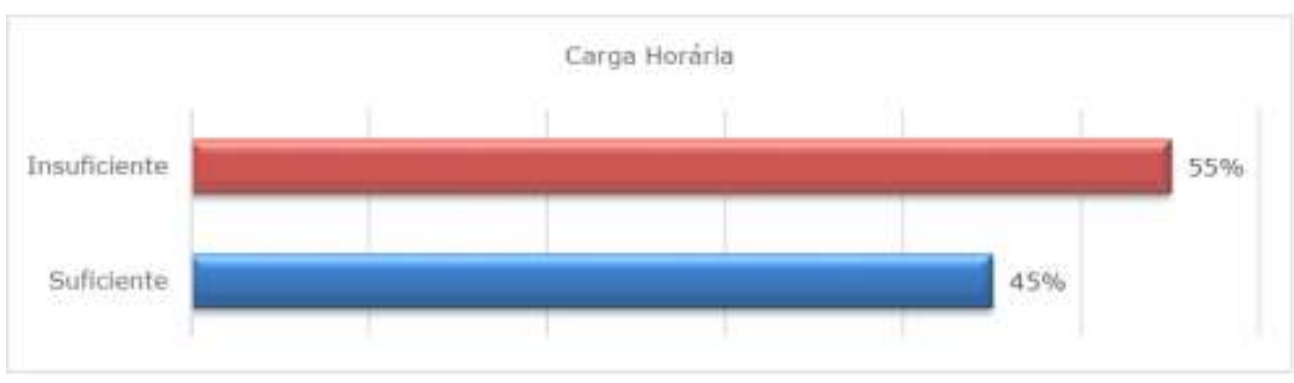

Fonte: Autores.

A maioria dos discentes destacam que a carga horaria deveria ser ampliada visando assim, detalhar os conteúdos complexos e de suma importância para a atualidade. As disciplinas de Botânica são amplas e com muitos conteúdos que acabam sendo repassados de forma muito rápida pelo professor, onde o aluno não consegue compreendê-lo. São muitas informações para serem abordados em um semestre e com isso alguns conteúdos são compactados ou não são ministrados totalmente por falta de tempo. Tal relato é ratificado no trabalho de Fonseca \& Ramos (2018), onde as disciplinas de Botânica na licenciatura apresentam uma carga horária menor em detrimento às outras disciplinas específicas do curso de Ciências Biológicas desfavorecendo o currículo da Botânica. No entanto, a discussão do currículo na licenciatura não é um trabalho fácil, mais essencial, pois temos que desenvolver formas de entendimento mais acessível ao ensino da Botânica (Dutra \& Güllich, 2016).

Para os licenciandos, a carga horária é distribuída inadequadamente entre aulas teóricas e práticas, onde o quantitativo de aulas práticas necessitaria aumentar para aprimorar e assimilar os conteúdos. Além disso, foi referido que o curso deveria oferecer mais disciplinas de Botânica, sendo uma específica ao ensino de Botânica. Nesse seguimento, fica perceptível a imprescindibilidade de repensar a grade curricular dos cursos de licenciatura pesquisados em relação às disciplinas de Botânica, visando desta forma uma boa formação acadêmica e didática do futuro docente.

\subsection{O contexto dos conteúdos de Botânica no processo ensino-aprendizagem}

A respeito dos conteúdos de Botânica ensinados pelos docentes, 54\% (63) dos licenciandos relatam que os mesmos não estão sendo aprendidos dentro de um contexto que facilita o processo ensino-aprendizagem (Figura 6). Para os alunos, o educador detém o conhecimento dos temas abordados na disciplina e esforçam-se em usar exemplos da realidade local. Mas, todavia, a metodologia utilizada ainda é mecânica e tradicional, fato esse que dificulta a aprendizagem. De acordo com Katon, Towata \& Saito (2013), o ensino de Botânica apresenta uma interpelação tradicional e descontextualizada, provocando desinteresse nos alunos. Sendo necessário subjugar essa prática nos cursos de licenciatura (Silva, 2013). Nessa circunstância, seria interessante, por parte dos educadores, a utilização de mais aulas práticas e contextualizadas, com a finalidade de tornar os conteúdos mais presente à realidade do aluno, facilitando assim a aprendizagem significativa. 
Figura 6. O contexto dos conteúdos de Botânica no processo ensino-aprendizagem.

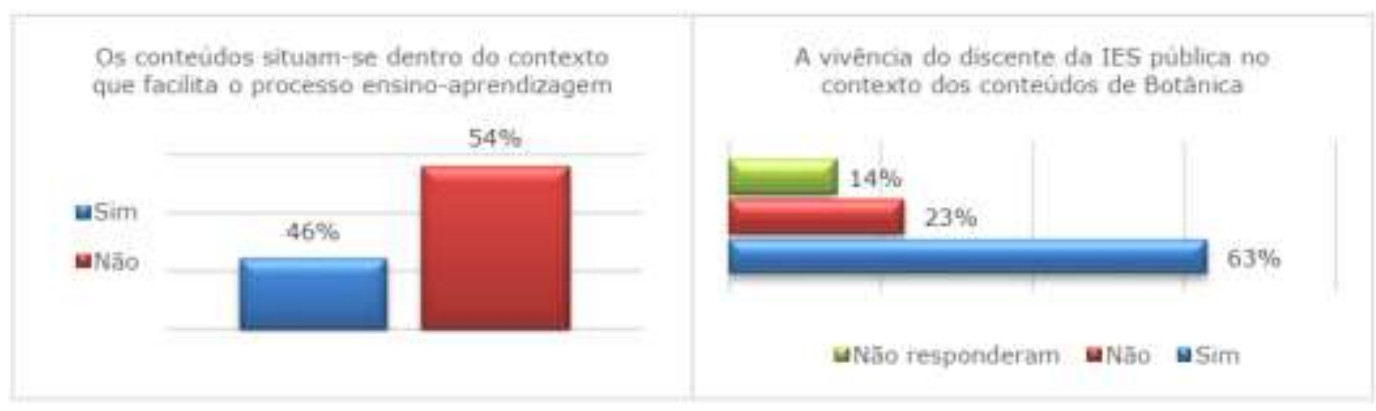

Fonte: Autores.

Apesar dos licenciandos declararem dificuldades em entender o contexto dos conteúdos botânicos, 63\% (74) dos partícipes atestam que em várias situações se deparam com a Botânica dentro da realidade de sua comunidade. Onde afirmam que, as disciplinas ministradas dessa área, estão inseridas dentro da realidade local da Amazônia, tornando-se possível visualizar as plantas de forma diferente, além de empenhar-se em reconhecer e identificar as suas estruturas (Figura 6). Antagonicamente, 23\% (27) dos discentes afirmaram que não conseguem entender os conteúdos de Botânica e desta forma não gostariam de apresentá-los e nem vivenciá-los. Pois os conhecimentos adquiridos durante a graduação apresentaram deficiências e ausência de práticas, não fornecendo segurança para desenvolver aulas que atinjam satisfatoriamente o aprendizado dos alunos na educação básica, dificultando assim, a atuação profissional fora da instituição de ensino superior. Segundo Fonseca \& Ramos (2018), o ensino da Botânica deve assumir uma conjuntura que simplifique a aprendizagem e que ao mesmo tempo fortaleça a relação entre as plantas e o ser humano. Todavia, a maneira como esses ensinamentos acontecem nos cursos de licenciatura em Ciências Biológicas contribui para o aposto a este contexto.

\subsection{O ambiente e as formas de aprender Botânica}

No tocante aos espaços onde ocorrem as aulas de Botânica, 47\% dos entrevistados relataram a ocorrência dessas somente em salas de aula (Figura 7). Circunstância que atesta uma atenuação das atividades práticas em detrimento da fixação dos conteúdos expostos no decorrer das aulas. As aulas práticas relacionam o que foi explicado em classe com a rotina do aluno, diminuindo as dificuldades de aprendizagem (Matos et al., 2015). Onde associar teoria com prática, torna o ensino de Botânica mais produtivo e competente, ocasionando ao discente experimentar os conteúdos de forma mais pragmática (Dutra \& Güllich, 2016; Ursi et al., 2018; Silva et al., 2021a). Por conseguinte, como melhorar a "cegueira botânica" dos licenciandos com ensinamentos somente em sala de aula? Pois esse tipo de aula não leva os alunos a perceber as plantas no seu próprio ambiente, ocasionando assim a incapacidade de perceber e reconhecer a importância delas para o meio ambiente.

Em relação à aprendizagem, 68\% dos discentes referenciam as aulas práticas (37\%) e as aulas de campo (31\%), associadas às aulas teóricas, como o melhor modo de aprender esses conteúdos (Figura 7). Esses resultados reforçam os estudos sobre a valorização das atividades práticas no ensino de Botânica (Araújo \& Silva 2013; Matos et al., 2015; Santos et al., 2015; Dutra \& Güllich, 2016; Ursi et al., 2018; Silva et al., 2021b). Essas atividades devem atuar como estratégia metodológica de ensino, despertando no acadêmico o interesse de construir o conhecimento almejado, ou seja, convertê-lo em sujeito dentro do processo de aprendizagem. Vale frisar que os graduandos admitem a relevância das aulas práticas ainda na formação profissional, o que torna isso muito importante, pois os mesmos tendem a realizar essa prática profissional, quando formados, aos seus futuros alunos. 
Figura 7. Local onde ocorrem as aulas e as formas de aprender Botânica.

$\begin{aligned} & \text { Espaços onde ocorrem as aulas de Botánica } \\ & \text { ESalas de aulas }\end{aligned}$
$=$ E Laboratórios
$=$ Aulas de campo

Fonte: Autores.

\subsection{O que pode ser melhorado no ensino de Botânica}

As principais melhorias para o ensino da Botânica, explicitados pelos discentes, foram aqui agrupados em tópicos: as aulas práticas, a carga horária das disciplinas, a metodologia docente, os laboratórios, a infraestrutura das IES e os recursos didáticos (Figura 8).

Figura 8. O que pode ser melhorado no ensino da Botânica.

\begin{tabular}{|c|c|}
\hline AULAS PRAIICAS & $\begin{array}{l}\text { - Uthizar mais aulas práticas } \\
\text { - Executar as aulas praticas durante a disciplina } \\
\text { - Correlacionar a teorla com a pratica }\end{array}$ \\
\hline CARGA HORARIA & - Aumentar a carga horária das disciplinas \\
\hline METODOLOGIA DOCENTE & $\begin{array}{l}\text { - Aperfeiçaar o planejamento e a execuçāo das aulas } \\
\text { - Despertar o interesse para a Botanica } \\
\text { - Contextualizar as aulas com a flora regional }\end{array}$ \\
\hline LABORATORIOS & $\begin{array}{l}\text { - Aprimorar e equipar os laboratórios do Campus } \\
\text { - Laboratório especifico de Botánica } \\
\text { - Colocar mais aulas de laboratorio }\end{array}$ \\
\hline INFRAESTRUTURA DA IES & $\begin{array}{l}\text { - Implementar no Campus o herbário, uma internet de melhor } \\
\text { qualidade estrutura para as aulas de botanica }\end{array}$ \\
\hline RECURSOS DIDATICOS & $\begin{array}{l}\text { - Maior disponibilidae de recursos financeiros para as viagens } \\
\text { - Mais recursos didaticos pedagógicos para as praticas de } \\
\text { ensino da botanica }\end{array}$ \\
\hline
\end{tabular}

Fonte: Autores.

Os licenciandos foram enfáticos em evidenciar o que pode ser melhorado no ensino da Botânica. As sugestões mencionadas (Figura 8) ratificam as dificuldades reputadas, por eles, para compreender esses conteúdos. As informações listadas, sugerem melhorias na formulação e no cumprimento das aulas práticas, e na contextualização e aperfeiçoamento das aulas teóricas. A relação demonstrada nos leva a refletir na aplicabilidade de aulas (teóricas e práticas) investigativas e contextualizadas como estratégia de ensino para minimizar as adversidades apresentadas, com o objetivo de valorizar o ensino da Botânica nos cursos de licenciaturas (Santos et al., 2015; Fonseca \& Ramos, 2018). Todavia, as estratégias de cunho administrativo, como a infraestrutura e aquisição de recursos e equipamentos metodológicos (Silva \& Moraes, 2011), cabem a cada IES pública buscar resolver essa problemática. 


\subsection{A aula de Botânica prazerosa e inesquecível na visão dos discentes}

Na perspectiva dos discentes, uma aula prazerosa de Botânica deve sempre apresentar uma prática de ensino como estratégia pedagógica (Figura 9). É importante relatar que, 77\% (90) dos discentes apontam as aulas práticas (teóricas e práticas, laboratório, campo) como principal instrumento de ensino para que as aulas de Botânica sejam prazerosas. Aliás, convêm referir que em algum momento, no ato de ensinar, podem faltar recursos ou condições para a realização dessas práticas (laboratórios e campo) ou teóricas, mas mesmo diante dessa problemática o professor não deve julgar suas aulas deficitárias, pois é possível com recursos simples e de fácil acesso ministrar aulas motivadoras e interessantes.

Figura 9. A aula de Botânica prazerosa na visão do discente.

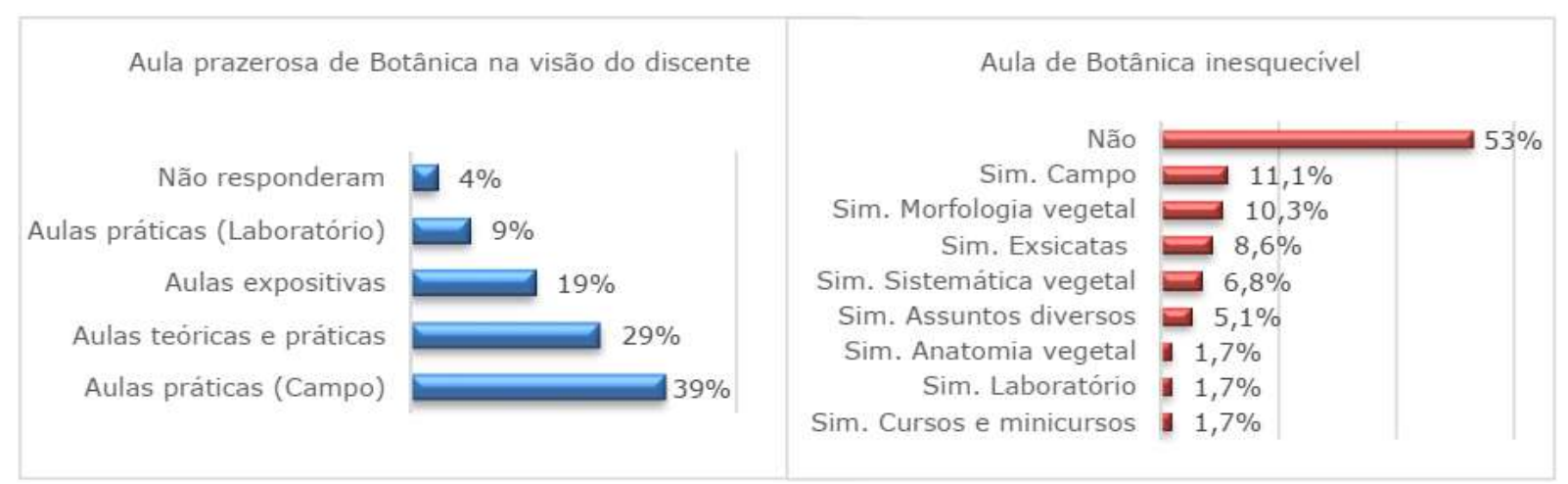

Fonte: Autores.

Diante do exposto, os licenciandos foram questionados se já tiveram alguma aula de Botânica inesquecível no decorrer do curso. Os relatos apontaram uma realidade preocupante, onde 53\% (62) dos discentes não vivenciaram, em nenhum momento da vida acadêmica, uma aula de Botânica considerada inesquecível. Episódio que ressalta o desinteresse em aprender esses assuntos durante o curso de formação profissional docente. Para 47\% (55) dos discentes houve uma aula inesquecível de Botânica durante a graduação, onde sobressaíram as experiências relacionadas às aulas práticas, na qual as aulas de campo se destacam como a principal aula inesquecível de Botânica. Esta veracidade retrata a relevância dessas aulas como estratégia de ensino e corrobora com os trabalhos que sustentam a importância dessas práticas, como ação complementar do processo ensino-aprendizagem (Krasilchik, 2008; Silva, 2013; Towata, Ursi \& Santos, 2010; Ursi et al., 2018; Silva et al., 2021b).

\section{Conclusão}

Os resultados retratados neste estudo indicam a imprescindibilidade de ponderar, no contexto apresentado, o ensino de Botânica nos cursos de Licenciatura em Ciências Biológicas e Naturais, visto que as dificuldades ressaltadas pelos licenciandos na aprendizagem de tais conteúdos referem-se principalmente as estratégias didáticas aplicadas pelos docentes no ensino das disciplinas e a exiguidade de aulas práticas. Nesse sentido, é imprescindível refletir sobre a metodologia docente aplicada ao ensino das disciplinas de Botânica, visando assim superar o conteudismo e a descontextualização dos conteúdos associado à carência das aulas práticas.

A diversificação das práticas de ensino tende a diminuir as adversidades apontadas pelos discentes na aprendizagem dos conteúdos de Botânica. Onde as estratégias de ensino, tal como a contextualização com abordagem CTSA, a interdisciplinaridade, a aprendizagem significativa e as aulas práticas envolvendo contexto investigativo e construtivo do conhecimento, podem estimular o interesse dos licenciandos pela Botânica. 
Sobre as melhorias no ensino de Botânica nos cursos de licenciatura enfatizamos a necessidade de realizar mais aulas práticas em conjunto com a revisão da carga horária das disciplinas, onde as mesmas são insuficientes para ministrar os conteúdos propostos pela ementa das disciplinas. Além do aprimoramento da elaboração e execução das aulas no ambiente de ensino por parte dos docentes, assim como a aquisição de recursos e equipamentos metodológicos destinados às aulas de Botânica.

Destacamos que esse trabalho é pioneiro no estado do Amapá e na região norte do Brasil para tal contexto. Os resultados atestam os estudos já efetuados em outras regiões do Brasil, fortalecendo ainda mais a importância de entender o que é experimentado em sala de aula, para aperfeiçoar o ensino de botânica em todos os níveis educacionais.

Pesquisas minuciosas sobre essa temática são primordiais, uma vez que releva a necessidade de averiguar novas estratégias para o ensino de Botânica nos cursos de Licenciaturas em Ciências Biológicas e Naturais. E baseado nessas informações será possível elaborar técnicas de aprendizagem e a criação de recursos didáticos para simplificar e direcionar, da melhor forma possível, a assimilação desses conteúdos pelos discentes nas IES.

\section{Referências}

Araújo, J. N., \& Silva, M. F. V. (2013). Floresta Amazônica: espaço não-formal potencial para aprender botânica. Anais do XI Congresso Nacional em Educação. Curitiba, PR: EDUCERE. Obtido de https://educere.pucpr.br/p1/anais.html

Bardin, L. (2011) Análise de conteúdo. São Paulo: Edições 70.

Dutra, A. P., \& Güllich, R. I. C. (2016). Ensino de Botânica: Metodologias, concepções de ensino e currículo. Ensino de Ciências e Tecnologia em Revista, 6(2), 39-53. doi: http://dx.doi.org/10.20912/2237-4450/v6i2.1541

Figueiredo, J. A., Coutinho, F. A., \& Amaral, F. C. (2012). O Ensino de Botânica em uma abordagem Ciência, Tecnologia e Sociedade. Revista de Ensino de Ciências e Matemática, 3(3), 488-498. doi: https://doi.org/10.26843/rencima.v3i3.420

Fonseca, L. R., \& Ramos, P. (2017). O Ensino de Botânica na Licenciatura em Ciências Biológicas: uma revisão de literatura. Anais XI Encontro Nacional de Pesquisa em Educação em Ciências. Florianópolis, SC: ENPEC. http://www.abrapecnet.org.br/enpec/xi-enpec/anais/listaresumos.htm

Fonseca, L. R., \& Ramos, P. (2018). Ensino de botânica na licenciatura em ciências biológicas de uma universidade pública do Rio de Janeiro: contribuições dos professores do ensino superior. Ensaio Pesquisa em Educação em Ciências (Belo Horizonte), 20, e11387, 1-23. doi: http://dx.doi.org/10.1590/1983211720182001026

Frasson, M. V., \& Campos, L. M. L. (2011). A opção pela licenciatura e pela profissão de professor: razões reveladas pelas vozes de licenciandos em Ciências Biológicas. VIII ENPEC - Encontro Nacional de Pesquisa em Educação em Ciências. Campinas, SP. http://abrapecnet.org.br/atas_enpec/viiienpec/listaresumos.htm

Freire, P. (1987). Pedagogia do oprimido. 17ª ed. Rio de Janeiro: Paz e Terra.

Freire, P. (1996). Pedagogia da autonomia: saberes necessários à prática educativa. 25a . ed. São Paulo: Paz e Terra.

Hershey, D. R. (2002). Plant blindness: "we have met the enemy and he is us". Plant Science Bulletin, 48(3), 78-85. https://www.botany.org/bsa/psb/2002/psb48-3.html?ref=s0d.org\#Plant

Katon, G. F., Towata, N., \& Saito, L. C. (2013). A cegueira botânica e o uso de estratégias para o ensino de botânica. Em A. M. Lopez [et al.]. (Org.), III Botânica no Inverno (pp. 179-183). São Paulo: Instituto de Biociências da Universidade de São Paulo.

Kinoshita, L. S., Torres, R. B., Tamashiro, J. Y., \& Forni-Martins, E. R. (2006). A botânica no ensino básico: relatos de uma experiência transformadora. São Carlos: RiMa.

Krasilchik, M. (2008). Prática de Ensino de Biologia. São Paulo: Editora da Universidade de São Paulo.

Lucas, M. C. (2014). Formação de professores de Ciências e Biologia nas décadas de 1960/1970: entre tradições e inovações curriculares. (Dissertação Mestrado em educação). Faculdade de Educação da Universidade Federal do Rio de Janeiro, Rio de Janeiro. https://ppge.educacao.ufrj.br/ppge-dissertacoes2014.html

Matos, G. M. A., Maknamara, M., Matos, E. C. A., \& Prata, A. P. (2015). Recursos didáticos para o ensino de botânica: uma avaliação das produções de estudantes em universidade sergipana. HOLOS, 31(5), 213-230. doi: 10.15628/holos.2015.1724

Pereira, A. S., Shitsuka, D. M., Parreira, F. J., \& Shitsuka, R. (2018). Metodologia da pesquisa científica. [free e-book]. Santa Maria, RS: Ed. UFSM, NTE.

Prigol, S., \& Giannotti, S. M. (2008). A importância da utilização de práticas no processo de ensino-aprendizagem de ciências naturais enfocando a morfologia da flor. $1^{\circ}$ Simpósio Nacional de Educação - XX Semana da Pedagogia. Cascavel/PR: UNIOESTE 
Research, Society and Development, v. 10, n. 5, e55210515250, 2021

(CC BY 4.0) | ISSN 2525-3409 | DOI: http://dx.doi.org/10.33448/rsd-v10i5.15250

Salatino, A., \& Buckeridge, M. (2016). Mas de que te serve saber botânica? Estudos avançados, 30(87), 177-196. doi: https://doi.org/10.1590/S010340142016.30870011

Santos, M. L., Oliveira, R. R. S., Miranda, S. C., \& Ramos, M. V. V. (2015). O Ensino de Botânica na formação inicial de professores em Instituições de Ensino Superior públicas no Estado de Goiás. Anais do X Encontro Nacional de Pesquisa em Educação em Ciências. Águas de Lindóia/SP: ABRAPEC. http://www.abrapecnet.org.br/enpec/x-enpec/anais2015/busca.htm

Silva, B. I. A., Mendes, J. C. R., Martins, M. B. S., Neto, P. G. M., Cerqueira, R. M., Macedo, T. M., \& Dias, A. C. A. A. (2019). O saber botânico através da seringueira: como conservar o que não conhecemos? Biota Amazônia, 9(2), 11-15. Obtido de https://periodicos.unifap.br/index.php/biota/search

Silva, J. A., Santos, T. V. A., Lucena, E. M. P., Bonilla, O. H., Pantoja, L. D. M., Edson-Chaves, B., Mendes, R. M. S. (2021a). Alunos do Ensino Médio da rede pública de Fortaleza-CE e o interesse pela Botânica. Research, Society and Development, 10(4), e18110413660. doi: http://dx.doi.org/10.33448/rsdv10i4.13660

Silva, J. N., Brito, M. V., Silva, J. S., Carvalho, M. R. V., Sá, G. H., Leite, H. H. B., Silva, V. B., Valente, S. E. S. (2021b). Estágio Supervisionado docente: Uma experiência vivenciada por licenciandos em Biologia em uma escola estadual de Teresina-PI. Research, Society and Development, 10(4), e10210413897. doi: http://dx.doi.org/10.33448/rsd-v10i4.13897

Silva, J. R. S. (2013). Concepções dos professores de Botânica sobre Ensino e Formação de Professores. (Tese Doutorado em Ciências na Área de Botânica) - Instituto de Biociências, Universidade de São Paulo, São Paulo. doi: https://10.11606/T.41.2013.tde-22072013-085700

Silva, J. R. S., \& Sano, P. T. (2011). O ensino de Botânica na visão dos estudantes de Ciências Biológicas. Atas do VIII Encontro Nacional de Pesquisa em Educação em Ciências - ENPEC. Campinas/SP: ABRAPEC. http://abrapecnet.org.br/atas_enpec/viiienpec/listaresumos.htm

Strauss, A., \& Corbin, J. (2008). Pesquisa Qualitativa: Técnicas e procedimentos para o desenvolvimento de teoria fundamentada. Porto Alegre: Artmed.

Towata, N., Ursi, S., \& Santos, D. Y. A. C. (2010). Análise da percepção de licenciandos sobre o Ensino de Botânica na educação básica. Revista da SBEnBio, 3(1), 1603-1612. Obtido de https://sbenbio.org.br/wp-content/uploads/edicoes/revista_sbenbio_n3/

Ursi, S., Barbosa, P. P., Sano, P. T., \& Berchez, F. A. S. (2018). Ensino de Botânica: conhecimento e encantamento na educação científica. Estudos Avançados, 32(94), 7-24. doi.org/10.1590/s0103-40142018.3294.0002

Ursi, S., Freitas, K. C., \& Vasques, D. T. (2021). Cegueira Botânica e sua mitigação: um objetivo central para o processo de ensino-aprendizagem de Biologia. In: Vasques, D. T., Freitas, K. C., \& Ursi, S. (Ed.) Aprendizado ativo no ensino de botânica. São Paulo: Instituto de Biociências, Universidade de São Paulo, Cap. 2, p. 12-30.

Wandersee, J. H., \& Schussler, E. E. (2001). Towards a theory of plant blindness. Plant Science Bulletin, 47(1), 2-9. https://botany.org/PlantScienceBulletin/psb-2001-47-1.php 